\title{
Libertad de pensamiento durante el confinamiento
}

\author{
Freedom of thought during the confinement \\ Ulyana MarchuK ${ }^{1}$ \\ Alumna de ASA Málaga (España)
}

\section{RESUMEN}

En este trabajo, defendido en la VIII Olimpiada de filosofía de Málaga, organizada por FICUM, se presenta la reflexión de una joven filósofa sobre su experiencia durante el confinamiento y cómo dicho confinamiento hace despertar en los jóvenes la pregunta filosófica por la libertad de pensamiento.

\section{PALABRAS CLAVES}

LIBERTAD, CONFINAMIENTO, REDES SOCIALES, PENSAMIENTO.

\section{ABSTRACT}

This essay, presented to the $8^{\text {th }}$ Philosophy Olympics in Málaga, organised by FICUM, presents a young philosopher's considerations about her experience during the confinement and how this confinement is responsible for the awakening in the youth of the philosophical question regarding the freedom of thought.

\section{KEYWORDS}

FREEDOM, CONFINEMENT, SOCIAL NETWORKS, THOUGHT.

¿QUÉ ES LA LIBERTAD? ¿SOMOS LibRes? ¿Hasta qué punto deberíamos serlo? Estas reflexiones parecen haber rondado por la cabeza de muchas personas a lo largo de la historia, pues conocemos varios ejemplos de filósofos que

1 Este trabajo ha sido seleccionado por un grupo de especialistas de entre los trabajos presentados a la VIII Olimpiada de Filosofía de Málaga organizada por FICUM en 2021. Como todos los trabajos publicados en esta revista, ha pasado por el correspondiente proceso de revisión por pares externos. De este modo, Claridades. Revista de Filosofía pretende contribuir al fomento de la filosofía entre los/as jóvenes de Málaga. 
trataban de definir la libertad y explicar cómo deberíamos vivir en una sociedad. Tenemos ejemplos como el de Aristóteles, que definía la libertad como la capacidad de decidir de forma racional y aceptar las consecuencias de estas decisiones, el de Sócrates, que asociaba el conocimiento con la libertad y la ignorancia con la esclavitud, e incluso el de Kant, que concibe la libertad como la capacidad de ponerse leyes a uno mismo y actuar de forma moral.

Pero no hace falta irse tan lejos para encontrar un concepto de libertad, pues este muta y es distinto para cada uno. Un esclavo puede concebir la idea de libertad como dejar de tener amo, o un prisionero asociar la libertad con salir de la cárcel. Incluso un estudiante puede pensar que su libertad llegará cuando se independice y viva solo. Cada uno puede pensar que le hará libre algo distinto, pero lo que veo en común es que lo que nos quita la libertad son los límites. Es decir, se podría definir la libertad como la falta de límites o tener la posibilidad de hacer todo lo que quieras, si es que quieres.

Sin embargo, por esta definición se diría que nadie llega a ser libre, ya que solo por el hecho de vivir en sociedad hay cosas que no podemos hacer o que si las hacemos podríamos ser castigados e, incluso, hay cosas a las que estamos limitados por el hecho de ser humanos, pues nunca podremos levantar grandes pesos como otros animales ni volar como pájaros. Aunque esto ya entraría en una definición de libertad más allá de nuestras posibilidades. No hay nadie que sea completamente libre, simplemente, hay personas que se acercarán más al concepto de libertad y otras que menos, y acercarnos más a libertad no tiene por qué hacernos más felices. ¿A qué es lo que me refiero exactamente y qué tiene que ver todo esto con el confinamiento?

\section{LIBERTAD Y CONFINAMIENTO}

Marzo de 2020. El Gobierno de Espańa comienza a darse cuenta de la gravedad del asunto del Covid, aquel extraño «virus de China». Ya no es solo una simple gripe, sino que comienza a extenderse rápidamente sin control. Es ahí cuando toman la decisión de confinar a toda la población, aunque no hay que preocuparse, no será durante mucho tiempo, seguramente unas dos semanas y poco más. 
Pero como todos sabemos, la historia no fue así. A esas dos semanas se le añadieron otras dos, y así sucesivamente hasta que alcanzamos unos tres meses, o eso creo recordar.

Unos meses en los que se les quitó a muchos adultos la posibilidad de salir a trabajar o de hacer sus asuntos, unos meses en los que casi nadie podía salir a pasear, unos meses en los que no podíamos vernos unos a otros, a menos que fuésemos parte de la misma familia. Límites y más límites, o como entiendo yo, falta de libertad.

Tampoco es que este confinamiento fuese tan terrible como otros acontecimientos de la historia, ha habido epidemias peores donde mucha gente ha tenido que vivir años encerrada, viendo de cerca la enfermedad y no pudiendo ayudar a los enfermos efectivamente. Pero esto no quita que el suceso de ahora nos haya afectado también en gran medida, y que los sentimientos que experimentamos sean parecidos a los que vivieron nuestros antepasados en eventos peores.

Las personas, queramos o no, no estamos acostumbrados a este tipo de cambios, y las emociones y cómo nos afecta pueden ser bastante parecidos.

Pensándolo bien, incluso tiene sentido que emocional y mentalmente nos pueda haber afectado en gran medida. Durante años ya se nos avisó de que esta sociedad estaba llena de personas deprimidas, ansiosas, reactivas. Viviendo incluso una gran época sin demasiados problemas parecíamos tener el estrés de un soldado de guerra.

Ahora imagina decirle a toda esa población con ansiedad y depresión, después de años en constante movimiento y productividad, que deben quedarse sin salir de casa. La preocupación por el dinero, el trabajo, el estrés que supone estar sin hacer casi nada después de tanto tiempo sin parar puede llegar a ser un gran problema, y de hecho recientemente se han visto artículos sobre la salud mental tras la pandemia.

Aún así, se entiende perfectamente el porqué del confinamiento, sacrificamos unos pocos meses, quitándonos libertades como salir a la calle para la seguridad de todos y que nos pudieran atender en caso de que nos contagiásemos. Tal vez, sin este pequeño sacrificio, la situación habría sido un completo desastre. 


\section{UN LADO POSITIVO, O NO}

A pesar de todo lo malo, durante esos meses de aburrimiento surgieron las personas creativas que ayudaron a hacer el confinamiento algo más ameno. Cada vez se unían más personas a las redes sociales y algunas de ellas trataban de hacer cosas entretenidas para sentirnos menos solos. La gente hablaba y se expresaba en Twitter, los streamers hacían directos a diario para acompañarnos por las tardes, los youtubers hacían retos interesantes para cultivar la creatividad.

Tampoco hace falta irse a internet, todos hemos visto vídeos de vecindarios elaborando conciertos desde sus casas para divertirse, gente haciendo deporte juntos desde sus terrazas, vecinos llevándose la compra unos entre otros cuando alguno se contagiaba.

Entre muchas personas se formó un gran ambiente de unión, donde podían expresarse, ser creativos y, en parte, ser libres.

Pero como sabemos, no es oro todo lo que reluce, y el que haya tanta gente nueva en redes sociales expresando sus ideas no es del agrado de todos. Muchos empezaron a atacarse unos a otros por sus opiniones, generando odio y recelo, ya que el ver discusiones constantemente termina cansando. También hubo una gran cantidad de desinformación respecto a la pandemia y bulos, tanto es así que algunas personas se plantearon crear un «Ministerio de la Verdad» para poder descartar información falsa. A mi parecer, esto habría supuesto un desastre porque, ¿quién decide en una opinión o en un dato dado a interpretación lo que es verdad o no? Es una herramienta peligrosa, pues muchos podrían utilizarla a su favor para restringir la opinión del resto.

Volviendo al odio de las redes sociales, nunca entenderé porque las personas están tan a la defensiva con sus opiniones. Creo firmemente que el debate y la libertad de pensamiento son una de las mejores cosas que podrían ocurrirle a una sociedad. Permiten expresarnos, encontrar nuevas alternativas, entender a los demás e incluso cambiar de punto de vista en ciertos aspectos y enriquecerte. Pero en los últimos años la población se ha vuelto demasiado reactiva, y a la mínima se dedican a insultar solo por pertenecer a un «bando» contrario, sin darte la libertad de expresar tu opinión.

Es cierto que en un momento como una pandemia es más fácil que ocurra esta falta de comprensión, la gente está encerrada, cansada y 
seguramente les apetezca discutir. Además, en ciertos temas no se puede permitir la desinformación y los bulos, ya que muchos de ellos eran sobre aspectos que afectan a la salud y podía ser peligroso.

Cambiando de tema, la única manera en la que nos afectó el confinamiento en cuanto a la libertad de pensamiento no es solo por redes sociales, sino que un gran factor es también nuestra propia mente, y en esto quería centrarme.

\section{LA MENTE Y LA LIBERTAD}

Los días eran repetitivos, aburridos y monótonos. Los contagios subían constantemente, la gente se preocupaba por su trabajo y sus ingresos y todas las noticias parecían ser negativas. $\mathrm{Y}$ a esto se le sumaba que nunca estábamos seguros de cuándo podríamos salir, aunque a muchas personas en realidad eso no les importó demasiado. Pero yo no paraba de pensar en que se me estaba quitando la libertad, lo que podía vivir y experimentar aquellos meses, y que día a día me estaba llenando de preocupaciones. Tampoco es que antes hiciese mucho más, pero el hecho de no tener la posibilidad de hacer algo es peor que hacerlo o no. Y esta es una de las cosas que más me ha dado que pensar.

He vivido ańos antes del confinamiento, donde podría haber salido a pasear más, quedar, ir de viaje, ir a una cafetería por la noche. Pero es cuando se me ha quitado la posibilidad de hacer esas cosas cuando verdaderamente las he apreciado y echado de menos, aunque tal vez no las habría hecho durante esos meses si no hubiese sabido acerca del confinamiento.

Es decir, siempre he pensado que no soy libre, porque hay miles de cosas que no puedo hacer, pero al quitarme la posibilidad de hacer muchas otras que antes sí podía, me he dado cuenta de lo libre que era antes, y la cantidad de libertad que todavía sigo teniendo, porque siempre hay gente en peores situaciones. Y aún así, aunque ahora aprecie todas esas cosas, mi mente sigue creyendo que no soy libre, y por muchas libertades que tenga, parece que nunca estaré contenta. Si se quitan las medidas de seguridad, tendré limitaciones porque necesito dinero para ir a sitios o hacer todas las cosas que quiero, si tengo dinero, tengo limitaciones por tener que gestionarlo. Si tengo emociones, me limito, porque me hacer pensar de forma irracional y no actuar en base a lo que de verdad quiero. Mi mente, 
mi forma de pensar, me limitan, porque soy yo la que piensa que no soy libre.

Y claro, siempre habrá hechos que de verdad nos están limitados. Estar confinados en casa, estar encerrados en una prisión, ser esclavos, son cosas que de verdad nos quitan libertad, la posibilidad de hacer elecciones que consideramos básicas. Incluso el entorno en el que podamos vivir, con unos padres poco permisivos y estrictos, puede ser determinante en esto.

Pero lo que vengo a decir es que hay cosas más allá de esto, y es que la forma de pensar de uno y como piensan otros te puede encerrar en ti mismo, condenarte a la idea de que no eres libre como si formaras tu propia cárcel mental, lo que considero bastante peligroso.

Poniendo por escrito esto, y dándome cuenta por qué mi mente considera que nunca seré libre, hacen que me replantee algunos asuntos: ¿Qué es la libertad? ¿Soy libre? ¿Hasta qué punto debería serlo?

Hasta cierto punto, siempre habrá condicionantes, siempre habrá sucesos que te impidan hacer lo que quieres, pero es cuando lo aceptas y luchas por hacer lo que deseas cuando de verdad haces algo productivo sin lamentarte tanto en la desgracia, y creo que ahí es verdaderamente cuando empezamos a tener cierta libertad. La lucha por la libertad será algo que esté siempre vigente en el ser humano, y creo que muchas personas de verdad deben perseguirla y alcanzarla, pero hay otros, como yo, que deberían pararse a pensar que en realidad ya lo eran bastante. 